\title{
Psychometric Properties of the Emotional Competence Inventory - Short Revised Version (ECI-R)
}

\author{
José Maurício Haas Bueno ${ }^{1}$ \\ Fernanda Maria de Lira Correia, 2 \\ Evandro Morais Peixoto ${ }^{3}$ \\ ${ }^{1}$ Universidade Federal de Pernambuco, Recife, Pernambuco, Brasil \\ ${ }^{2}$ Centro Universitário Estácio Recife, Recife, Pernambuco, Brasil \\ ${ }^{3}$ Universidade São Francisco, Campinas, São Paulo, Brasil
}

\begin{abstract}
A previous study presented the Emotional Competence Inventory, which was designed with basis on the emotional intelligence theory. It was very long and had a disproportionate number of items for each factor. Therefore, this study aimed to seek for validity evidence based on its internal structure and carry out an analysis of items of the short version of the instrument supported by the Item Response Theory (IRT). The study included 626 Brazilian participants with a mean age of 24.8 years (SD = 8.2). They were predominantly females $(68.5 \%)$ who answered to the 34 items in the instrument. A confirmatory factor analysis showed good fit indices, thus confirming the original structure of the instrument. IRT analyses also resulted in good fit indices and revealed the aspects involved in the increased difficulty of the items in each scale. It was concluded that the instrument shows good psychometric properties and can be recommended for research purposes.
\end{abstract}

Keywords: emotional intelligence; emotions; emotion regulation.

Propriedades Psicométricas do Inventário de Competências Emocionais - Versão Revisada Breve (ICE-R)

\begin{abstract}
Resumo
Um estudo anterior apresentou o Inventário de Competências Emocionais, construído com base na teoria da inteligência emocional, que ficou muito longo e com número desproporcional de itens em cada fator. Assim, a proposta desse estudo foi buscar evidências de validade com base na estrutura interna e proceder uma análise de itens com base na Teoria de Resposta ao Item da versão reduzida do instrumento. O estudo contou com 626 participantes brasileiros, com média de 24,8 anos de idade $(D P=8,2)$, predominantemente do sexo feminino $(68,5 \%)$, que responderam os 34 itens do instrumento. Uma análise fatorial confirmatória mostrou bons índices de ajustamento, confirmando a estrutura original do instrumento. A análise com TRI também resultou em bons índices de ajustamento e permitiu identificar os aspectos envolvidos no aumento da dificuldade dos itens em cada escala. Concluiu-se que o instrumento apresenta boas propriedades psicométricas e pode ser recomendado para uso em pesquisas.

Palavras-chave: inteligência emocional, emoções, regulação emocional.
\end{abstract}

Propiedades Psicométricas del Inventario de Habilidades Emocionales - Versión Corta Revisada (ICE-R)

\begin{abstract}
Resumen
Un estudio previo presentó el Inventario de Habilidades Emocionales, basado en la teoría de la inteligencia emocional, que era demasiado extenso y con un número desproporcionado de ítems en cada factor. Por lo tanto, la finalidad de este estudio fue buscar evidencias de validez basadas en la estructura interna y realizar un análisis de ítems basado en la Teoría de Respuesta al Ítem de una versión reducida del instrumento. El estudio incluyó 626 participantes brasileños, con una edad media de 24,8 años (DS $=8,2)$, predominantemente mujeres $(68,5 \%)$, que respondieron a los 34 ítems del instrumento. Un análisis factorial confirmatorio mostró buenos índices de ajuste, confirmando la estructura original del instrumento. El análisis con el TRI reveló los aspectos involucrados en el aumento de la dificultad de los ítems en cada escala. Se concluyó que el instrumento tiene buenas propiedades psicométricas y puede ser recomendado para usos investigativos.

Palabras claves: inteligencia emocional; emociones; regulación emocional.
\end{abstract}

\section{Introduction}

Emotional intelligence (EI) is a cognitive ability related to the processing of emotional information. In its most recent theoretical formulation, EI is composed of four basic abilities: perception of emotions, use of emotion to facilitate thought, emotional understanding and regulation of emotions (Mayer, Caruso, \& Salovey, 2016).

The perception of emotions is an ability that involves the recognition of emotions in oneself and in other people, objects or environments; the identification of genuine or falsified emotional expressions and the ability to express emotions by the usual means, such as 
speech, the face and body movement. The use of emotion to facilitate thought is associated with the use of emotion as a warning sign, which directs thought to the most important information, both internal and external, so that it can be used in decision-making processes. Emotional understanding concerns the knowledge of emotions, their differences and meanings, encompassing the understanding of the events that trigger them and of the behaviors that tend to arise as their result, as well as the capacity to understand complex feelings, such as mixed emotions and the transition from one feeling to another. Finally, the regulation of emotions refers to the ability to understand emotional reactions, pleasant or not, to control and/or discharge them in an appropriate way to the demands from the environment, aiming to promote personal growth in oneself and in other people (Mayer et al., 2016).

Currently, two positions related to the conceptual field of EI have been pointed out, one that understands it as a trait and another as an ability (Mayer et al., 2016; Petrides, 2017). From the perspective of ability, EI is understood as the capacity to perceive and understand emotional information in order to achieve more appropriate behaviors to the context presented. From the perspective of trait, also referred to as emotional self-efficacy or perceived emotional intelligence, EI is related to the self-perception of emotional competencies and can take into account non-cognitive abilities, such as optimism and empathy, characteristics that are usually related to personality traits, and that are associated with success in life. These differences, however, reflect more the type of instrument used to measure emotional intelligence - whether by performance (ability) or self-reporting (trait) - than the concept of EI itself (Petrides, 2017). With this regard, the definition of EI presented can be operationalized both from a cognitive perspective, through performance instruments (for example, Mayer, Salovey, Caruso, \& Sitarenios, 2003) or from the trait perspective, through self-report instruments (for example, Schutte et al., 1998).

In this study, interest falls on the perspective of EI as a trait, within which there are instruments based on different theoretical perspectives. Following, we describe the main self-report instruments that were constructed based on Mayer et al. (2016) theoretical perspective, that we also adopted in this study.

The first instrument designed to assess the EI trait was the Emotional Intelligence Scale, consisting of 33 statements to be answered using a five-point Likert scale. Initially, a unifactorial structure was obtained, with an internal consistency of 0.90 (Schutte et al., 1998), but further studies resulted in a factorial solution with four components (optimism/mood regulation; evaluation of emotions, social abilities and use of emotions), as well as a general second-order factor (Petrides \& Furnham, 2000; Saklofske, Austin \& Minski, 2003).

The Emotional Skills and Competence Questionnaire (ESCQ) (Takšić, 1998) contains 45 items, which are divided into three primary factors (perception and understanding of emotions, expression and naming of emotions and management and regulation of emotions) and a general second-order factor, with good reliability indices. The scale was built in the Croatian cultural context and translated into other languages, including European Portuguese, in which it obtained a similar structure to the original questionnaire (Faria et al., 2006).

The Swinburne University Emotional Intelligence Test (SUEIT) is a self-report measure, developed for the Australian population (Palmer \& Stough, 2001). The instrument has 64 items to be answered using a five-point Likert scale and presents a structure with five factors: recognition and expression of emotions, direct cognition of emotions, knowledge of external emotions, management of emotions and emotion control. The internal consistency indices ranged from 0.63 to 0.88. Luebbers, Downey and Stough (2007) developed a SUEIT version for Australian adolescents. It consists of of 57 items that were organized in a primary structure of four factors, which were similar to those in thee original test (with the exception of the emotion control factor), and in a general second-order factor. Cronbach's alpha coefficients were 0.85 for the general factor and ranged from 0.75 to 0.81 for the primary factors.

The Wong and Law Emotional Intelligence Scale (WLEIS) (Wong \& Law, 2002) is a self-report scale with 16 items that assess the four dimensions of EI using a seven-point Likert scale. A confirmatory factor analysis resulted in two satisfactory models, one unifactorial model and another with the four factors corresponding to EI abilities. The internal consistency indices were all greater than 0.8. Cross-cultural studies attested to the factorial invariance of WLEIS (Fukuda, Saklofske, Tamaoka \& Lim, 2012; Libbrecht, by Beuckelaer, Lievens \& Rockstuhl, 2014).

These instruments are examples of self-report measures built in other countries, based on the theory by Mayer and Salovey, which present compatible factors, but are distinct from the structure originally 
proposed by the authors. In addition, these studies do not show an analysis at the item level, which could help to advance in the identification and understanding of the aspects that make them easier or more difficult. This is a point that this study seeks to advance by proposing that such analysis be carried out with support from the Item Response Theory (IRT).

Some of the aforementioned instruments have recently been translated into Brazilian or European Portuguese and have shown good psychometric properties, such as TEIQue-SF (Perazzo et al., 2020) and Schutte's Emotional Intelligence Scale (Satuf et al., 2020), but the lack of an instrument to assess the emotional intelligence trait at the time led a group of researchers to design the Emotional Competence Inventory (ECI) (Bueno, Correia, Abacar, Gomes \& Pereira Júnior, 2015). This instrument consists of 68 items to be answered using a five-point Likert scale. An exploratory factor analysis showed a primary-factor structure with five factors (perception of emotions $(\alpha=0.91)$, regulation of lowpower emotions $(\alpha=0.83)$, emotional expressiveness $(\alpha=0.67)$, regulation of emotions in other people $(\alpha$ $=0.86)$ and regulation of high-power emotions $(\alpha=$ 0.77). Furthermore, a higher-order factor was obtained, in which only the primary factor of emotional expressiveness did not have a factor load greater than 0.3 , thus suggesting the possibility of a second-order factorial structure.

Despite the good psychometric properties obtained, the authors recommended its review in later studies, especially as there is a very large variability in the number of items for each factor (from five to 29 items), which implies content redundancy and an unnecessary increase in the time for application of the instrument. According to the authors, the elimination of excess items based on robust procedures, such as the Item Response Theory, could result in a short version of the instrument, maintaining good psychometric properties and the same estimation capacity of the evaluated construct (Bueno et al, 2015).

In addition, the regulation of emotions showed important facets that had never been captured by other tests and may indicate the existence of different mental processes for emotion control in oneself and in other people. Also, emotion control in oneself was subdivided into two factors: one that refers to the control of high-power emotions (those that motivate behaviors on impulse) and one that refers to the control of low-power emotions (those that motivate the flight or distancing from the stimulus and/or the environment). The authors suggest the need to confirm the achievement of these factors with another sample of participants (Bueno et al., 2015).

The factors listed reaffirm the importance of continuing studies with ECI, which can become a shorter but yet valid and reliable instrument for assessing the perceived emotional competencies in the Brazilian population. With this regard, the present study was developed, the objectives of which were to seek evidence of validity based on internal structure, to evaluate the reliability indices of the factors obtained and to carry out an analysis of the items of a short version of the instrument based on the Item Response Theory.

\section{Method}

\section{Participants}

This study included 626 participants, whose ages ranged from 15 to 62 years, with a mean of 24.8 years $(\mathrm{SD}=8.2)$ and, of these, $68.5 \%$ were females $(1 \% \mathrm{did}$ not report sex). In addition, they were predominantly university students or professionals with higher education $(79.9 \%)$, of mixed race, including brown-skinned/ black $(53.5 \%)$ and white $(44.5 \%)$ individuals, with an income that was less than four minimum wages $(63.6$ $\%$ ), from the state of Pernambuco (72.5\%).

\section{Instrument}

The revised version of the Emotional Competence Inventory (ECI-R) was obtained by selecting 34 among the 68 items that composed the final version of the original ECI study (Bueno et al, 2015). For item selection, the following indicators were taken into account: indices of difficulty of items (parameter $b$ of IRT), magnitudes of the factorial loads of the items in the corresponding factors and reliability indices. Thus, through the observation of the difficulty indices (b), it was possible to identify items that assessed the same level of ability, being, therefore, redundant and unnecessary. When there were two or more items at the same ability level, the decision on which to eliminate was based on the observation of factor loads and factor reliability indices, preferring the elimination of those with lower factor loads and/or which caused a smaller drop in reliability indices.

The items in this version describe emotional abilities to be read and answered using a five-point Likert scale, where 1 means "It doesn'tt apply to me", and 5 means "It perfectly applies to me". The statements represent the five factors obtained in the original version of 
the instrument: perception of emotions (for example, "I quickly notice it when a feeling is dangerously increasing in intensity"), emotional expressiveness (for example, "I can easily express what I feel'), regulation of emotions in other people (for example, "I can help other people to feel better"), regulation of low-power emotions in oneself (for example, "I can easily get rid of sadness") and regulation of high-power emotions in oneself (for example, "I can control my irritation"). In addition, a brief questionnaire was applied in order to collect information to characterize the sample, such as sex, age, place of birth, education and ethnicity.

\section{Procedures}

After the project was approved by a Research Ethics Committee (CAAE: 07085412.2.0000.5208), participants were contacted through social networks and invitations were sent by email. When clicking on the link to the survey, participants were greeted by a thank-you and welcome screen. The next screen contained the Informed Consent Form (ICF), whose terms had to be accepted by the participants as a requirement for access to the next section. The next section contained a brief questionnaire to characterize the sample and the Revised Emotional Competence Inventory. The participants' answers were automatically stored on an electronic spreadsheet and later submitted to statistical analysis.

\section{Data analysis}

The validity of the instrument based on its internal structure was investigated through confirmatory factor analysis (CFA), using the second-order factor model, in which the items were distributed in the five primary factors obtained in a previous study (Bueno et al., 2015), and, in turn, the five primary factors were grouped under a general second-order factor, theoretically related to emotional competencies. Only item 5, which in the previous study had been under "highpower emotion regulation" was transferred to the "emotion regulation in other people" factor, as it is theoretically more compatible with such factor.

The Weighted Least Squares Mean and Varianceadjusted (WLSMV) estimator, available in the lavaan package (Rosseel, 2012) for R (R Core Team, 2018), which is recommended for ordinal data and samples with more than 200 participants, was used, as this the case in the present study (Li, 2015). The following data adjustment indicators for the model were used: adjusted chi-square $\left(\chi^{2 / g l}\right)$, Root Mean Square Error of Approximation (RMSEA), Standardized Root Mean Residual (SRMR), Comparative Fit Index (CFI) and the Tucker-Lewis Index (TLI). The adjusted chi-square $\left(\chi^{2} / \mathrm{gl}\right)$ must be less than 2, RMSEA and SRMR less than 0.08 , and CFI and TLI must be greater than 0.90 (Kline, 2005; Schumacker \& Lomax, 2010).

In order to check the reliability of primary factors, the alpha and omega coefficients were calculated, based on polychoric correlations, which are more appropriate for ordinal data. For the second-order factor, the same coefficients were used, but based on Pearson's correlations. These analyses were implemented in the psych package (Revelle, 2018) for R (R Core Team, 2018), with values expected to exceed 0.7 (Peixoto \& FerreiraRodrigues, 2019).

Item analysis was performed using the Item Response Theory (IRT), with parameter estimation by Andrich's Rating Scale Model, a model of the Rasch family (1 parameter), with the Joint Maximum Likelihood estimation method, which assumes that items share the same scheduling structure (Linacre, 2015). The indices of adjustment (infit and outfit) of the data to the model, the parallelism between the thresholds of the response categories and the five-point scale were checked. Additionally, a content analysis based on the difficulty indices of the items in each scale was performed.

In order to check the fitting of the items to the IRT model, the infit and outfit indices were used, whose values between 0.5 and 1.5 are indicative of good fitting (Linacre, 2002). Parallelism is confirmed when the theta values at the thresholds between the response categories show a pattern of progressive increase in value; and the difficulty indices must: a) spread evenly over a wide range of abilities, and b) increase according to an aspect related to the content of the items that compose each factor. Analysis was performed using the Multidimensional Item Response Theory (MIRT) package (Chalmers, 2012) for R (R Core Team, 2018).

\section{Results}

The CFA results are shown below, followed by the reliability indices and the analysis of items based on IRT. Table 1 shows the lambda coefficients of the regression equations, calculated according to the WLSMV estimator.

The item coefficients (in module) for the EE factor were between 0.60 and 0.81 ; for the RLPE factor, they ranged from 0.53 to 0.83 ; for the PE factor, they 
Table 1.

Lambda coefficients of the regression equations

\begin{tabular}{|c|c|c|c|c|}
\hline $\begin{array}{c}\text { General Factor } \\
2^{\text {nd }} \text { order }\end{array}$ & $\begin{array}{c}\text { Lambdas } \\
\left(2^{\text {nd }} \text { order }\right) \\
\end{array}$ & Primary Factors & $\begin{array}{l}\text { Lambdas } \\
\text { (primary) }\end{array}$ & items \\
\hline \multirow{34}{*}{$\mathrm{EC}$} & \multirow{4}{*}{0.50} & \multirow{4}{*}{$\mathrm{EE}$} & 0.64 & i32 \\
\hline & & & -0.60 & $\mathrm{i} 28$ \\
\hline & & & 0.76 & i18 \\
\hline & & & 0.81 & i06 \\
\hline & \multirow{7}{*}{0.69} & \multirow{7}{*}{ RLPE } & 0.83 & i27 \\
\hline & & & 0.76 & $\mathrm{i} 24$ \\
\hline & & & 0.70 & $\mathrm{i} 21$ \\
\hline & & & -0.53 & i16 \\
\hline & & & 0.75 & i14 \\
\hline & & & 0.73 & i11 \\
\hline & & & 0.63 & i04 \\
\hline & \multirow{7}{*}{0.74} & \multirow{7}{*}{ PE } & 0.57 & i33 \\
\hline & & & 0.54 & $\mathrm{i} 22$ \\
\hline & & & 0.64 & i19 \\
\hline & & & 0.62 & i12 \\
\hline & & & 0.39 & i10 \\
\hline & & & 0.55 & i07 \\
\hline & & & 0.50 & i02 \\
\hline & \multirow{7}{*}{-0.76} & \multirow{7}{*}{ RHPE } & -0.40 & i34 \\
\hline & & & -0.58 & $\mathrm{i} 30$ \\
\hline & & & -0.63 & i25 \\
\hline & & & -0.63 & $\mathrm{i} 20$ \\
\hline & & & 0.44 & i17 \\
\hline & & & -0.63 & i13 \\
\hline & & & 0.27 & i03 \\
\hline & \multirow{9}{*}{0.78} & \multirow{9}{*}{ REO } & 0.81 & i31 \\
\hline & & & 0.78 & i29 \\
\hline & & & 0.78 & i26 \\
\hline & & & 0.70 & i23 \\
\hline & & & 0.77 & i15 \\
\hline & & & 0.50 & i09 \\
\hline & & & 0.72 & i08 \\
\hline & & & 0.56 & i05 \\
\hline & & & 0.55 & i01 \\
\hline
\end{tabular}

EE - Emotional Expressiveness, RHPE - Regulation of Low-Power Emotions in Oneself, PE - Perception of Emotions, RHPE - Regulation of High-Power Emotions in Oneself, REO - Regulation of Emotions in Other People and EC - Emotional Competencies.

were from 0.39 to 0.64 ; for the RHPE factor, from 0.27 to 0.63 , and for the REO factor, from 0.50 to 0.81 . Yet, the coefficients of primary factors for the second-order 
factor (EC) ranged from 0.50 to 0.78 . The indices for fitting the data to the model are shown in Table 2.

The indices suggest goodness of fit of the data to the structure with five primary factors (regulation of emotions in other people, regulation of low-power emotions in oneself, emotional expressiveness, perception of emotions and regulation of high-power emotions in oneself) and a second-order factor (emotional competencies). Only one item (i03) showed a load of 0.27 for the RHPE factor, but due to the compatibility of its content with the factor and because it did not impair the reliability of the factor, it was maintained in the structure. The internal consistency indices for each factor, measured by Cronbach's alpha and McDonald's omega coefficients, are shown in Table 3.

It is noted that all coefficients were equal to or greater than 0.7, as expected (Peixoto \& Ferreira-Rodrigues, 2019). Then, the analyses were carried out based on the Item Response Theory, using the MIRT package, for R. Table 4 shows the infit and outfit indexes, the thresholds and the difficulty indices of the items, based on Rasch's model of the Item Response Theory.

The data in Table 2 show that all infit and outfit indices are within the expected range, from 0.5 to 1.5 (Linacre, 2002), showing a good fit of the data to Rasch's model of the Item Response Theory. The thresholds follow a sequence of progressive value increase, indicating that all response categories (on the five-point Likert scale) are more likely to be endorsed in some region of the emotional abilities assessed by the factors. An exception occurred for the PE factor, whose category 2 is not the most likely in any regions of the abilities. Finally, the analysis of the difficulty indices of the items (b) shows that, on all scales, the items are concentrated in a very narrow range of the ability spectrum (less than one logit in most cases), around theta equal to zero. It is noteworthy, however, that, in the anchoring procedure, the difficulty means of the items were set at zero, which made it possible to compare the extent of the theta level assessed by the factors. The information

Table 2.

Adjustment Indices

\begin{tabular}{ll}
\hline Indices & Values \\
\hline Chi-square & $\chi 2=1787.035$ \\
& $\mathrm{gl}=522$ \\
& $\mathrm{p}<0.001$ \\
Comparative Fit Index & $\mathrm{CFI}=0.967$ \\
Tucker-Lewis Index & $\mathrm{TLI}=0.964$ \\
Root Mean Square Error of Approximation & $\mathrm{RMSEA}=0.062$ \\
Standardized Root Mean Residual & SRMR $=0.067$ \\
\hline
\end{tabular}

Table 3.

Internal consistency coefficients

\begin{tabular}{ccc}
\hline Factors & $\begin{array}{c}\text { Cronbach's } \\
\text { Alpha }\end{array}$ & McDonald's Omega \\
\hline REO & 0.88 & 0.88 \\
RLPE & 0.87 & 0.87 \\
EE & 0.79 & 0.79 \\
PE & 0.76 & 0.76 \\
RHPE & 0.71 & 0.72 \\
EC & 0.70 & 0.73 \\
\hline
\end{tabular}

Obs.: The alpha and omega coefficients for the primary factors were calculated based on polychoric correlations, which are more appropriate for ordinal data. The coefficients for the general factor were calculated based on Pearson's correlations. 
Table 4.

Adjustment indices, thresholds and difficulty

\begin{tabular}{|c|c|c|c|c|c|c|c|c|}
\hline Scale & Item & Outfit & Infit & t1 & $\mathrm{t} 2$ & t3 & $\mathrm{t} 4$ & $\mathrm{~b}$ \\
\hline \multirow{9}{*}{ REO } & i01 & 1.118 & 1.125 & \multirow{9}{*}{-1.827} & \multirow{9}{*}{-1.589} & \multirow{9}{*}{-0.093} & \multirow{9}{*}{1.058} & 0.000 \\
\hline & i05 & 1.195 & 1.225 & & & & & 0.819 \\
\hline & i08 & 0.829 & 0.825 & & & & & -0.400 \\
\hline & i09 & 1.301 & 1.345 & & & & & 0.927 \\
\hline & i15 & 0.783 & 0.803 & & & & & 0.294 \\
\hline & i23 & 0.711 & 0.723 & & & & & 0.819 \\
\hline & i26 & 0.691 & 0.701 & & & & & -0.279 \\
\hline & i29 & 0.753 & 0.788 & & & & & 0.244 \\
\hline & $i 31$ & 0.685 & 0.702 & & & & & 0.139 \\
\hline \multirow{7}{*}{ RLPE } & i04 & 0.922 & 0.928 & \multirow{7}{*}{-1.401} & \multirow{7}{*}{-0.977} & \multirow{7}{*}{0.174} & \multirow{7}{*}{0.870} & 0.000 \\
\hline & i11 & 0.935 & 0.974 & & & & & 0.481 \\
\hline & i14 & 0.848 & 0.862 & & & & & 0.400 \\
\hline & i16inv & 1.200 & 1.188 & & & & & -0.313 \\
\hline & i21 & 0.756 & 0.750 & & & & & -0.404 \\
\hline & i24 & 0.816 & 0.821 & & & & & 0.221 \\
\hline & i27 & 0.554 & 0.551 & & & & & 0.058 \\
\hline \multirow{4}{*}{ EE } & i06 & 0.624 & 0.647 & \multirow{4}{*}{-1.103} & \multirow{4}{*}{-0.674} & \multirow{4}{*}{-0.122} & \multirow{4}{*}{0.356} & 0.000 \\
\hline & i18 & 0.687 & 0.753 & & & & & 0.657 \\
\hline & i28inv & 0.881 & 0.911 & & & & & -0.180 \\
\hline & i32 & 0.749 & 0.781 & & & & & 0.027 \\
\hline \multirow{7}{*}{$\mathrm{PE}$} & i02 & 0.844 & 0.889 & \multirow{7}{*}{-1.367} & \multirow{7}{*}{-1.593} & \multirow{7}{*}{-0.967} & \multirow{7}{*}{-0.07} & 0.000 \\
\hline & i07 & 0.845 & 0.901 & & & & & -0.171 \\
\hline & i10 & 1.099 & 1.288 & & & & & 0.667 \\
\hline & i12 & 0.866 & 0.910 & & & & & -0.167 \\
\hline & i19 & 0.732 & 0.758 & & & & & -0.213 \\
\hline & i22 & 1.010 & 1.048 & & & & & -0.014 \\
\hline & i33 & 0.834 & 0.905 & & & & & 0.368 \\
\hline \multirow{7}{*}{ RHPE } & I03inv & 1.092 & 1.093 & \multirow{7}{*}{-0.421} & \multirow{7}{*}{-0.349} & \multirow{7}{*}{0.386} & \multirow{7}{*}{0.910} & 0.000 \\
\hline & i13 & 0.843 & 0.854 & & & & & 0.615 \\
\hline & i17 & 0.858 & 0.867 & & & & & 0.262 \\
\hline & i20 & 0.728 & 0.729 & & & & & 0.327 \\
\hline & i25 & 0.679 & 0.676 & & & & & 0.028 \\
\hline & $i 30$ & 0.674 & 0.667 & & & & & 0.409 \\
\hline & i34 & 1.207 & 1.224 & & & & & -0.058 \\
\hline
\end{tabular}

Note: $\mathrm{t}=$ threshold

and standard-error curves for the five scales are shown in Figure 1.

The information curve of the RLPE scale had its peak close to theta equal to zero, that of $\mathrm{PE}$ was approximately -0.5 , those of REO and EE were around 0.5 , and that of RHPE close to 1 . All scales, however, showed amplitude of the range in which the level of information is greater than the error of approximately 


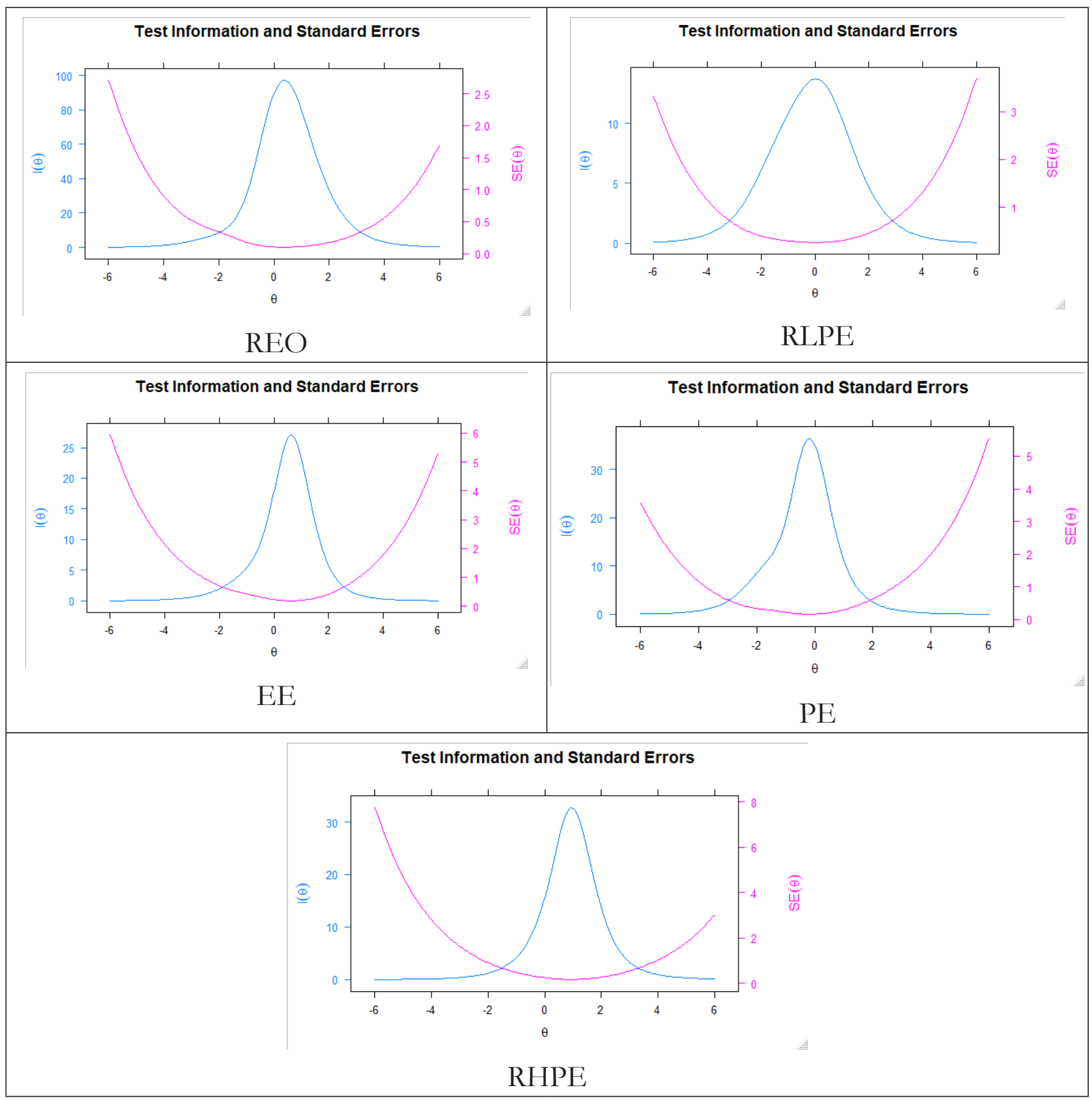

Figure 1. Curves of information and standard errors of the scales.

4 logits, suggesting that they cover a good extension of the spectrum of abilities to deal with emotions.

\section{Discussion}

To achieve the objectives proposed in this study, confirmatory factor analysis was performed to investigate internal structure, and an analysis of the items using IRT was carried out. The results of these analyses will be discussed in that order, as follows.

The fitting indices obtained in the confirmatory factor analysis suggest that the short scale maintains the factor structure of the original scale (Bueno et al., 2015), with the five primary factors (regulation of emotions in 
other people, regulation of low-power emotions in oneself, emotional expressiveness, perception of emotions and regulation of high-power emotions in oneself) and a second-order factor, related to the general competence to deal with emotions. An analysis of the content of the items that compose these factors allows us to interpret them as follows.

The REO factor involves the ability to deal with emotionally troubled or situationally and emotionally overwhelmed people, the ability to calm someone without discouraging him/her or to motivate someone without embarrassing him/her, helping others to feel better in order to face their difficulties and give the best of themselves. The RLPE factor involves the ability to not let oneself be overwhelmed by sadness, discouragement, melancholy or fear, the ability to overcome everyday frustrations through self-motivation and the generation of appropriate feelings in oneself to deal with the tasks to be carried out. EE involves the ability to express oneself emotionally, both from the point of view of communicating feelings and of unblocking shame or fear of non-acceptance by others. PE involves the ability to perceive emotional states and changes in oneself and others, being able to detect the influence of one's own behavior on others' feelings and the influence of others' behavior on one's own feelings, to detect the difference between what is socially expected to feel in certain situations and what one really feels, or to quickly detect that a feeling is dangerously increasing in intensity. RHPE involves the regulation of impulsivity, both of anger and of euphoria, in order to be able to control oneself so as to act appropriately to the situation presented. And finally, the General Emotional Competence Factor represents the general ability to deal with emotional situations, to perceive emotions in oneself and in others, without exaggerating or diminishing their importance, to express oneself emotionally, and to control both emotions that tend to produce impulsive behaviors (such as anger and euphoria) and those that tend to produce paralysis, discouragement and low energy for action.

These factors are compatible with those obtained in previous studies. The factor related to the perception of emotions (PE), for example, is compatible with factors evaluation of emotions (Schutte et al., 1998), perception and understanding of emotions (Faria et al., 2006; Takšić, 1998), recognition and expression of emotions (Palmer \& Stough, 2001) and perception of emotions (Wong \& Law, 2002). Similar factors to emotional expressiveness (EE) were obtained by Faria et al.
(2006) and Takšić (1998), with factor expression and naming of emotions, and by Palmer and Stough (2001), such as factor recognition and expression of emotions.

In turn, aspects related to the regulation of emotions in oneself and in other people were observed for three factors in ECI-R (REO, RLPE and RHPE). The two factors concerning regulation of emotions itself (RLPE and RHPE) can be classified as intrinsic emotion regulation strategies, as they involve the management of emotions that the person himself/herself experiences, while the regulation of emotions in other people (REO) can be understood as an extrinsic regulation strategy (Gross, 2015).

Other instruments have shown a multifactorial structure for the regulation of emotions, such as the Emotion Regulation Profile (ERP), for example, whose factors are organized around the idea of downand up-regulation of negative and positive emotions, respectively (Gondim et al., 2015). In the case of ECI-R, however, these concepts apply to the aspect related to the power of emotions, that is, to how much an emotion drives an individual towards contact with the source-object of the emotion (anger and euphoria, for example), or how much an emotion drives to escaping or avoiding the source-object of the emotion (such as sadness, fear and disgust, for example). With this regard, the power of emotions such as anger and euphoria usually needs to be reduced (similarly to the down-regulation process), and the power of emotions such as sadness, fear and disgust needs to be increased (similarly to the up-regulation process). Therefore, these factors were called regulation of high- and lowpower emotions.

ERP, however, was designed to assess the regulation of emotions, while ECI-R evaluates other aspects of emotional processing, such as the perception and expression of emotions. In similar instruments to ECI$\mathrm{R}$, the regulation of emotions usually appears in a single factor, under the general name of management and regulation of emotions (Faria et al., 2006; Takšić, 1998), management of emotions and emotion control (Palmer \& Stough, 2001) or regulation of emotions (Wong \& Law, 2002).

Another difference in ECI-R is the scale for regulation of emotions in other people (REO), which seems to be more associated with relational abilities, since it involves the handling of emotions that other people experience. These nuances of emotion regulation strategies are contributions that come from obtaining these factors both in the original instrument and in its short 
form, and they suggest that the ability to regulate emotions may involve other aspects, in addition to those already discussed in the literature.

In addition, a unifactorial solution or a general second-order factor has also been found in previous studies. These were the cases of the Emotional Intelligence Inventory (Schutte et al., 1998; Saklofske et al., 2003), the Swinburne University Emotional Intelligence Test (Luebbers et al., 2007) and the Wong and Law Emotional Intelligence Scale (Iliceto \& Fino, 2017), whose general factors constitute a global indicator of individuals' emotional competence. These occurrences are also compatible with the Emotional Intelligence Theory, which advocates the occurrence of a general emotional-intelligence factor, such as the one responsible for performances in specific factors (Mayer et al., 2016).

It was also noted that the amplitude of the indices of greater and lesser difficulty in each factor was predominantly less than 1 logit (except for the REO factor). In part, this may reflect a common problem to instruments for assessing emotional intelligence by performance, namely that of creating difficult items. It turns out that emotional problems can have (and usually have) more than one way to be addressed and resolved. Therefore, when the creation of a more difficult item is attempted, a more ambiguous item, which accepts more varied responses, is eventually designed. And the elimination of these items results in reducing the amplitude of the difficulty indices. This occurrence was also observed in previous studies, both for selfreport instruments (Ricarte, Silva \& Bueno, 2019) and for performance instruments (Noronha, Primi, Freitas \& Dantas, 2007).

The reliability of these factors can also be considered excellent, since all the alpha and omega coefficients were above 0.7, as expected (Peixoto \& FerreiraRodrigues, 2019). These indices improved as compared to those obtained with the original instrument (Bueno et al, 2015) and are compatible with those found in other studies, such as the Emotional Intelligence Inventory (Schutte et al., 1998; Saklofske et al., 2003), the Swinburne University Emotional Intelligence Test (Palmer \& Stough, 2001), the Emotional Skills and Competence Questionnaire (Faria et al., 2006; Takšić, 1998) and the Wong and Law Emotional Intelligence Scale (Wong \& Law, 2002). In addition, the good performance of ECI-R in terms of reliability was also confirmed by the analysis of items using IRT, which showed that most scales have their reliability increased by values close to theta equal to zero (except for the RHPE factor), but it spans approximately 4 logits in the ability continuum. Thus, it can be said that individual differences in ECI-R scores can be attributed more to true differences in the construct under consideration than to measurement errors (Peixoto \& Ferreira-Rodrigues, 2019).

The analysis of the content of the items, when organized by their difficulty indices, also showed that it is possible to identify the elements by which the described behaviors become more difficult to be endorsed by the participants, which is also an indicator of the developmental processes of the emotional competencies under consideration. For example, in relation to the REO scale, there was good amplitude (1.327 logit) between the least (i8) and the most difficult (i9) item. The easiest items are to calm someone who is in the grip of high-power emotions (euphoria and anger). It is a little more difficult to encourage or motivate people to deal with low-power emotions (sadness, fear) without discouraging or embarrassing them. And, at a level of greater difficulty is the understanding of other people from their point of view, which seems to presuppose the development of empathy. This result is compatible with the findings by Guzman, Bird, Banissy and Catmur (2016), for example, which showed that physiological and behavioral responses related to empathy can be developed through intervention, by improving the quality of social interactions.

In the REB scale, the amplitude between the theta means of the extreme items was only 0.885 logit, that is, the difficulty of the items is concentrated in the same range of abilities, which makes it more difficult to identify the aspects that hinder the acquisition of competency as to that ability. Even so, it is possible to identify that the easiest items refer only to being able to come out (or not) of a low-power negative emotional state (sadness, discouragement), and the most difficult already mention knowing strategies to deal with these feelings or coming out of a negative emotional state to a positive one (and not only getting rid of the negative emotional state). Such interpretation is compatible with the positive results that have been obtained with intervention programs that teach strategies to avoid negative low-power emotions (such as sadness and guilt, for example) and to transition from that emotional state to more positive emotional states, as is the case of interventions based on mindfulness (for example, Creswell, 2017) and on emotional intelligence (for example, Fernández-Berrocal \& Extremera, 2016) with depressive patients. This suggests that knowledge of strategies 
for dealing with low-power emotions, such as sadness and guilt, can make a difference for people suffering from mood disorders, for example.

The amplitude of the difficulty indices of the items on the EE scale was 0.837 . The easiest item to be endorsed by the participants refers to being ashamed to express what one feels, followed by two items referring only to being emotionally expressive, while the most difficult item mentions expressing positive feelings towards someone. In fact, Lin (2016) found that the expression of positive emotions is associated with increased self-esteem and emotional stability and low depression and anxiety. These data are compatible with the greater complexity of positive emotional expressiveness directed to other people, found in the present study.

The PE scale also showed lower amplitude than one logit (0.880) between the items with the lowest (i19) and highest (i10) levels of difficulty. The easiest item is related to the perception of emotions in other people, followed by items related to the perception of emotions in oneself (perception of discrepancy between what you should or would like to be feeling and what you really feel, and perception of increase in the intensity of an emotion). Then comes a block of items with intermediate difficulty (close to zero), which refer to the identification of environmental aspectst that act under the very emotional state. And the most difficult item to be endorsed describes an apparently confusing situation, in which the person perceives a nonspecific negative feeling (feeling bad), without knowing the cause for it.

Finally, the RHPE scale concentrated items in the ability range that requires low competence, with amplitude of 0.673 logit. It is possible to observe that the easiest items to be endorsed are those that involve the control of the emotion-associated behavior and not of the emotion itself. This type of emotion regulation has been referred to in the scientific literature as response modulation or suppression, and it is considered a poorly adaptive strategy for regulating emotions (Goldin, Moodie \& Gross, 2019; Gross, 2015). Subsequent difficulty items involve controlled emotional expression to achieve a desired relational effect. In fact, managing emotions in oneself to achieve a desired result is the most elaborate strategy for regulating emotions, in the theoretical system of emotional intelligence (Mayer et al., 2016). In order to achieve such effect, in general, acceptance, reevaluation and problem-solving strategies are used, which are considered adaptive strategies for emotion regulation (Goldin, Moodie \& Gross, 2019).

This set of results allows us to state that the revised version of the Emotional Competence Inventory (ECI-R) is an instrument with good psychometric properties that can be recommended for use in research in the Brazilian cultural context. However, based on the results presented, the instrument still requires further studies to: a) expand the spectrum of abilities achieved by the instrument's scales, b) better represent factors such as emotional expressiveness, which was left with only three items, c) try to represent other factors theoretically related to emotional intelligence and that are not included in this instrument, such as the use of emotion to facilitate thought and the understanding of emotions, among others.

\section{Concluding remarks}

This study aimed to seek validity evidence based on internal structure and proceed with an analysis of items of the instrument based on IRT for a revised version with fewer items of the Emotional Competence Inventory (Bueno et al., 2015). Based on the results presented, this study contributes to advance the evaluation of the emotional intelligence trait in the Brazilian cultural context by providing a compact and reliable instrument to assess compatible emotional competencies with this theory. In addition, the study also provides support for advancing scientific knowledge on emotional intelligence by confirming the three factors related to different nuances of emotion regulation, by highlighting developmental aspects that make items more difficult and that are of interest not only for the continuity of the instrument's development, but also for psychologists and researchers interested in interventions to develop these abilities.

Some points, however, constitute limitations to this study, such as the collection performed exclusively on the internet and predominantly with female participants from the northeastern region and with higher education (in progress or concluded). In addition, it is necessary to expand the knowledge on what can be inferred from the test scores (validity), the trustworthiness of its scores (reliability) and the possible bias of the items in specific groups (item analysis). These characteristics limit the generalization of results for populations with the same characteristics as those employed in this study and highlight the need for continuity and diversification of psychometric studies on 
the instrument. Despite this, the study presents a compact instrument with good psychometric properties for assessing emotional competencies, especially in scientific investigations.

\section{References}

Bueno, J. M. H., Correia, F. M. L., Abacar, M., Gomes, Y. D. A., \& Júnior, F. S. P. (2015). Competências emocionais: Estudo de validação de um instrumento de medida. Avaliação Psicológica, 14(1), 153-163. doi: 10.15689/ap.2015.1401.17

Chalmers, R. P. (2012). MIRT: A multidimensional item response theory package for the $\mathrm{R}$ environment. Journal of Statistical Software, 48(6), 1-29. doi: 10.18637/jss.v048.i06

Creswell, J. D. (2017). Mindfulness interventions. Annual Review of Psychology, 68(1), 491-516. doi: 10.1146/ annurev-psych-042716-051139

Faria, L., Santos, N. L., Takšić, V., Räty, H., Molander, B., Holmström, S., \& Toyota, H. (2006). Cross-cultural validation of the Emotional Skills and Competence Questionnaire (ESCQ). Psicologia, 20(2), 95-127. Recuperado de: http://www. scielo.mec.pt/scielo.php?script $=$ sci_arttext\&pi$\mathrm{d}=$ S0874-20492006000200005\&lng=pt\&tlng=.

Fernández-Berrocal, P., \& Extremera, N. (2016). Ability emotional intelligence, depression, and well-being. Emotion Review, 8(4), 311-315. doi: $10.1177 / 1754073916650494$

Fukuda, E., Saklofske, D. H., Tamaoka, K., \& Lim, H. (2012). Factor structure of the Korean version of Wong and Law's Emotional Intelligence Scale. Assessment, 19, 3-7. doi: 10.1177/1073191111428863.

Goldin, P., Moodie, C., \& Gross, J. (2019). Acceptance versus reappraisal: Behavioral, autonomic, and neural effects. Cognitive, Affective, \& Behavioral Neuroscience. doi: 10.3758/s13415-019-00690-7

Gondim, S. M. G.; Pereira, C. R.; Hirschle, A. L. T.; Palma, E. M. S.; Alberton, G. D.; Paranhos, J.; Santana, V. \& Ribeiro, W. R. B. (2015). Evidências de validação de uma medida de características pessoais de regulação das emoções. Psicologia: Reflexão e Crítica, 28(4), 659-667. doi: 10.1590/1678-7153.201528403
Gross, J. (2015). Emotion regulation: Current status and future prospects. Psychological Inquiry, 26(1), 1-26. doi: 10.1080/1047840x.2014.940781

Guzman, M.; Bird, G; Banissy, M. J.; Catmur, C. (2016). Self-other control processes in social cognition: From imitation to empathy. Philosophical Transactions B, B371: 20150079. doi:10.1098/ rstb.2015.0079

Iliceto, P., \& Fino, E. (2017). The Italian version of the Wong-Law Emotional Intelligence Scale (WLEISI): A second-order factor analysis. Personality and Individual Differences, 116, 274-280. doi: 10.1016/j. paid.2017.05.006

Kline, R.B. (2005), Principles and practice of structural equation modeling (2nd Edition ed.). New York: The Guilford Press.

Li, C. (2015). Confirmatory factor analysis with ordinal data: Comparing robust maximum likelihood and diagonally weighted least squares. Behavior Research Methods, 48(3), 936-949. doi: 10.3758/ s13428-015-0619-7

Libbrecht, N., De Beuckelaer, A., Lievens, F., \& Rockstuhl, T. (2014). Measurement invariance of the Wong and Law Emotional Intelligence Scale scores: Does the measurement structure hold across far eastern and European countries? Applied Psychology, 63, 223-237. doi: 10.1111/j.1464-0597.2012.00513.x.

Lin, M. (2016). Reliability and validity of a self-report emotional expressivity measure: The Japanese version of the Berkeley expressivity questionnaire. Japanese Journal of Nursing Science, 13(1), 196-201. doi:10.1111/jins.12094

Linacre, J. M. (2002). What do infit and outfit, mean-square and standardized mean. Rasch Measurement Transactions, 16(2), 878. Recuperado de https://www.rasch.org/rmt/rmt162f.htm, em 25/07/2-19.

Linacre, J. M. (2015). Winsteps Rasch Measurement Computer Program User's Guide. Beaverton, OR Winsteps.com.

Luebbers, S., Downey, L. A., \& Stough, C. (2007). The development of an adolescent measure of EI. Personality and Individual Differences, 42(6), 999-1009. doi: 10.1016/j.paid.2006.09.009

Mayer, J. D., Salovey, P., Caruso, D. R., Sitarenios, G. (2003). Measuring emotional intelligence with Psico-USF, Bragança Paulista, v. 26, n. 3, p. 519-532, jul./set. 2021 
the MSCEIT v2.0. Emotion, 3, 97 - 105 doi: 10.1037/1528-3542.3.1.97

Mayer, J. D.; Caruso, D. R. \& Salovey, P. (2016). The ability model of emotional intelligence: Principles and updates, Emotion Review, 8(4), p.290-300. doi:10.1177/1754073916639667

Noronha, A., Primi, R., Freitas, F., \& Dantas, M. (2007). Análise dos itens do Mayer-Salovey-Caruso Emotional Intelligence Test: Escalas da área estratégica. Psicologia em Estudo, 12(2), 415-422. doi: 10.1590/ s1413-73722007000200023

Palmer, B., \& Stough, C. (2001). Workplace SUEIT: Swinburne University Emotional Intelligence Test - technical manual. Organizational Psychology Research Unit, Swinburne University, Australia.

Peixoto, E. M. \& Ferreira-Rodrigues, C. F. (2019). Propriedades psicométricas dos testes psicológicos. Em Makilim Nunes Baptista et al. (Eds), Compêndio de Avaliação Psicológica (pp. 29-39). Petrópolis, RJ: Vozes.

Perazzo, M., Abreu, L., Pérez-Díaz, P., Petrides, K., Granville-Garcia, A., \& Paiva, S. (2020). Trait Emotional Intelligence Questionnaire-Short Form: Brazilian Validation and Measurement Invariance between the United Kingdom and Latin-American Datasets. Journal of Personality Assessment, 1-10. doi: 10.1080/00223891.2020.1758118

Petrides, K. V. (2017). Intelligence, Emotional, Reference Module in Neuroscience and Biobehavioral Psychology, 1-6. doi:10.1016/B978-0-12-809324-5.05601-7

Petrides, K. V., \& Furnham, A. (2000). On the dimensional structure of emotional intelligence. Personality and Individual Differences, 29(2), 313-320. doi:10.1016/s0191-8869(99)00195-6

R. Core Team (2018). R: A language and environment for statistical computing. $R$ Foundation for Statistical Computing, Vienna, Austria. URL http://www. Rproject. org.

Revelle, W. (2018) psych: Procedures forpersonality and psychological research, Northwestern University, Evanston,
Illinois, USA. URL https://CRAN.R-project.org/ package $=$ psych Version $=1.8 .12$

Rosseel, Y. (2012). lavaan: An R package for structural equation modeling. Journal of Statistical Software, 48(2). doi: 10.18637/jss.v048.i02

Saklofske, D. H.; Austin, E. J., \& Minski, P. S. (2003). Factor structure and validity of a trait emotional intelligence measure. Personality and Individual Differences, 34(4), 707-721. doi: 10.1016/ S0191-8869(99)00195-6

Satuf, C., Monteiro, S., Esgalhado, G., Pereira, H., Afonso, R., Loureiro, M., \& Barbosa, M. (2020). Perceived emotional intelligence assessment The Portuguese validation of Schutte's Emotional Intelligence Scale (SEIS-P). Avaliação Psicológica, 19(1), 18-28. doi: 10.15689/ap.2020.1901.14814.03

Schumacker, R. E., \& Lomax, R. G. (2010). A beginner's guide to structural equation modeling (3rd Edition), New York: Taylor \& Francis Group.

Schutte, N. S., Malouff, J. M, Hall, L. E., Haggerty, D. J., Cooper, J. T., Golden, C. J., \& Dornheim, L. (1998). Development and validation of a measure of emotional intelligence. Personality and Individual Differences, 25(2), 167-177. doi: 10.1016/ S0191-8869(98)00001-4

Takšić, V. (1998). Validacija konstrukta emocionalne inteligencije. [Validation of the emotional intelligence construct]. (Tese de doutorado não publicada), University of Zagreb, Croácia

Wong, C. S. \& Law, K. S. (2002). The effects of leader and follower emotional intelligence on performance and attitude: An exploratory study. The Leadership Quarterly, 13, 243-274. doi: 10.1016/ S1048-9843(02)00099-1.

Recebido em: 26/07/2019

Reformulado em: $17 / 08 / 2020$

Aprovado em: 01/09/2020 
About the authors:

José Maurício Haas Bueno holds a PhD degree in Psychology from Universidade São Francisco (2008), and he is a professor at Universidade Federal de Pernambuco, where he coordinates the Center for Studies in Psychological Assessment. He also conducts, supervises and publishes scientific research with emphasis on the construction and adaptation of psychological assessment instruments and on intervention programs toward emotional intelligence development.

ORCID: https://orcid.org/0000-0002-9179-7216

E-mail: mauricio.bueno@ufpe.com

Fernanda Maria de Lira Correia is a Psychologist with a Master's degree in Cognitive Psychology. She is currently a PhD student in Cognitive Psychology at Universidade Federal de Pernambuco and a member of the Center for Studies in Psychological Assessment, in which she develops studies on the construction of psychological assessment instruments. She also works as a professor at Centro Universitário Estácio do Recife.

ORCID: https://orcid.org/0000-0002-0412-3273

E-mail: fernandalira.psi@gmail.com

Evandro Morais Peixoto is a Professor in the Graduate Program in Psychology at Universidade São Francisco (USF). He has a Master's and a Doctoral degree in Psychology as a Profession and Science from Pontifícia Universidade Católica de Campinas. He developed doctoral studies at Université du Québec à Trois-Rivières UQTR (Canada) as well as post-doctoral studies at USF.

ORCID: https://orcid.org/0000-0003-1007-3433

E-mail: evandro.peixoto@usf.edu.br

Contact:

Endereço: Av. da Arquitetura, s/n - CFCH, $8^{\circ}$ Andar

Recife-PE, Brasil

CEP: 50670-901 